\title{
Simulation of Laser Thermal Interaction with Titanium Dioxide /Polyvinyl Alcohol Nanocomposite Thin Films
}

\author{
A.M.Shehap \\ Physics Department \\ Cairo University \\ Cairo,Egypt
}

\author{
Dana.S.Akil \\ Cairo University \\ Cairo,Egypt
}

\begin{abstract}
The aim of this work is to use the computational simulation to define the operational conditions to achieve the desired process. The diagnostic tests were used to guide the experiment where PVA composites doped with Titanium dioxide nanoparticles were irradiated with nitrogen laser in order to modify its properties. The temperature of the samples with different laser fluencies were simulated using finite element method, in COMSOL program, to predict the fluencies that is suitable to use for modification before reaching the decomposition temperature of the nanocomposite sample to make sure not to cause any damage. The optical and thermal properties were experimentally studied, and the results were used to define the absorption coefficient and the thermal conductivity of the studied nanocomposites
\end{abstract}

Keywords: Polymer nanocomposite; Simulation ; pulsed laser ; heat equation .

\section{INTRODUCTION}

There are various chemical and physical changes caused when materials exposed to electromagnetic radiation. The ability to use the laser to affect a specific and small spot have a great advantage to use in manufacturing integrated circuits and control properties.[1] Many researchers deal with the interaction of laser irradiation with doped polymer films. Laser was used to change the optical structural and thermal properties of polymers and polymers composites like crystalinity and band gap $[2,3]$. Laser effect on thin films can be simulated by numerical methods to define the operational conditions. Which included minimizing heat effect zone, reaching the melting point ,or reaching ablation threshold.

Computer-assisted technologies for product design usually based on numerical methods, that are able to solve a set of algebraic equations to obtain desired results, in determined boundary conditions of process. Numerical programs are used to calculate tensions, shifts, vibration, heat transfer, fluid flow, and other process parameters [4]

In this work, the COMSOL program is used to build a numerical model capable of simulating the heat transfer and predict the temperature distribution on a thin film of $\mathrm{TiO}_{2} / \mathrm{PVA}$ nanocomposited after irradiated by Nitrogen pulsed laser. The aim of this work is to define the Laser dynamic range for modifying the prepared nanocomposites before damaging (i.e the temperature of the nanocomposite does not exceed decomposition temperature of the nanocomposite)

\section{THE PROPERTIES OF THE STUDIED NANOCOMPOSITES}

The optical properties of the $\mathrm{TiO}_{2}$ /PVA prepared nanocomposites with different doping percentage $(1.25,2.5,5$, $7.5,10 \% \mathrm{TiO}_{2} / \mathrm{PVA}$ ) were studied. The PVA Pure films have absorption band of wavelength $\lambda=198 \mathrm{~nm} 208 \mathrm{~nm}$ and at 281 $\mathrm{nm}$ assigned [25], theses three absorption bands are followed by transparency region. It can be understood that the absorption of the Nitrogen laser is neglected since PVA does not have an absorption peak around $337 \mathrm{~nm}$ which is the wavelength of the Nitrogen laser. But in the case of the doped PVA films with $\mathrm{TiO}_{2}$, a new absorption peak can be noticed around $388 \mathrm{~nm}$ which correspond to the absorption of the $\mathrm{TiO}_{2}$ nanoparticles.It can be seen that the absorption increases by increasing the dopant in the matrix .Table (1) illustrate the absorption coefficient for each nanocomposite film .

\section{LASER ABSORPTION IN $\mathrm{TIO}_{2} / \mathrm{PVA}$ NANOCOMPOSITE}

Doping PVA polymer with $\mathrm{TiO}_{2}$ nanoparticles increase the composite absorption of the Nitrogen laser. As the laser is absorbed mostly by the nanoparticles and not by the PVA chemical bonds, we can neglect the photochemical effect and consider the laser effect thermally. The absorbed part of the laser energy in the nanocomposite depend on its properties including reflectivity and absorption which both depend on the wavelength of the laser wavelength .To study the laser thermal effect and temperature distribution we be consider the absorbed laser energy as heat source which is given by [5]:

$$
\mathrm{Q}(\mathrm{r}, \mathrm{t})=\alpha \mathrm{I}_{0}(\mathrm{r}, \mathrm{t})(1-\mathrm{R}) \exp (-\alpha \mathrm{z})
$$

Where $\alpha$ and $\mathrm{R}$ are the absorption coefficient and the reflectivity of the nanocomposite film at the laser wavelength . I is the laser power intensity which depend on time and on the beam shape (which is Gaussian in this case).

The last part of the equation is related to the fact that the laser energy absorption decrease exponentially with depth from the sample surface $(\mathrm{z})[6]$

$$
\mathrm{I}(\mathrm{z})=\mathrm{I}_{0} \mathrm{e}^{-\mathrm{az}}
$$

The penetration depth of the laser is related to the skin depth for the electromagnetic field

$$
\delta=\frac{1}{\alpha}=\frac{\lambda}{4 \pi n^{\prime}(\lambda)}
$$

Where, $n^{\prime}(\lambda)$ is the imaginary part of the complex index of the refraction of the material. $\delta$ is the shield depth of the electromagnetic radiation. The thin film of the nanocomposites in our case has $50 \mu \mathrm{m}$ thickness which is much smaller than the 
penetration depth of the laser, so we can neglect the variation of laser energy with depth.

\section{HEAT EQUATION}

We used the COMSOL 4.3 to solve the following heat equation:

$$
\nabla^{2} \mathrm{~T}(\mathrm{r}, \mathrm{t})+\frac{1}{\mathrm{k}} \mathrm{Q}(\mathrm{r}, \mathrm{t})=\frac{1}{\alpha} \frac{\partial \mathrm{T}(\mathrm{r}, \mathrm{t})}{\partial \mathrm{t}}
$$

And find the temperature distribution in order predict the laser intensity that could cause damage in the nanocomposite film which means to reach its decomposition temperature.

The prepared nanocomposite films were found to have more stability as the doping ratio increased, as was found by thermal studying of nanocomposites, the decomposition temperature $\left(T_{d}\right)$ is found to increase as illustrated in table (1) Thermal conductivity is a very important factor in the heat equation which is equal to $0.2 \mathrm{~W} /(\mathrm{m} . \mathrm{K})$ for PVA but increases for the composites because of the $\mathrm{TiO}_{2}$ doping which has a thermal conductivity about (3.62) W/(m. K) Maxwell calculated the effective thermal conductivity (ETC) of a random distribution of spheres in a continuous medium for low filler concentration [7] as:

$$
\mathrm{k}_{\mathrm{e}}=\mathrm{k}_{\mathrm{m}} \frac{\mathrm{k}_{\mathrm{f}}+2 \mathrm{k}_{\mathrm{m}}+2 \varphi\left(\mathrm{k}_{\mathrm{f}}-\mathrm{k}_{\mathrm{m}}\right)}{\mathrm{k}_{\mathrm{f}}+2 \mathrm{k}_{\mathrm{m}}-\varphi\left(\mathrm{k}_{\mathrm{f}}-\mathrm{k}_{\mathrm{m}}\right)}
$$

Where $\mathrm{k}_{\mathrm{e}}, \mathrm{k}_{\mathrm{m}}$ and $\mathrm{k}_{\mathrm{f}}$ are effective thermal conductivity ,matrix thermal conductivity and thermal conductivity of fillers , respectively, and $\varphi$ is the volume fraction of inclusions. The calculated values of thermal conductivity of the nanocomposites is illustrated in table (1)

Table 1. experimental values of thermal conductivity, decomposition temperature and absorption coefficient for

\begin{tabular}{|c|c|c|c|}
\hline $\begin{array}{l}\text { Sample } \\
\mathrm{TiO}_{2} / \mathrm{PVA} \\
(\mathrm{wt} / \mathrm{wt} \%)\end{array}$ & $\begin{array}{l}\mathrm{k} \\
{[\mathrm{W} /(\mathrm{m} . \mathrm{K})]}\end{array}$ & $\mathrm{T}_{\mathrm{d}}\left[\mathrm{C}^{\circ}\right]$ & $\begin{array}{l}\alpha \\
{[\mathrm{cm}-1]}\end{array}$ \\
\hline 0 & 0.2 & 288 & 36.54 \\
\hline $1.5 \%$ & 0.208 & 290 & 201.66 \\
\hline $2.5 \%$ & 0.213 & 302 & 391.57 \\
\hline $5 \%$ & 0.2269 & 304 & 475.81 \\
\hline $7.5 \%$ & 0.2413 & 306 & 1023.60 \\
\hline $10 \%$ & 0.3412 & 319 & 1093.16 \\
\hline
\end{tabular}
$(\lambda=337 \mathrm{~nm})$

\section{SIMULATION AND RESULTS}

We can solve the equation using the COMSOL. The films are having the dimension ( $3 \mathrm{~cm}$ radius and $0.05 \mathrm{~cm}$ thickness). The initial temperature is $(300 \mathrm{~K})$. The laser energy $(0.375 \mathrm{~J})$, the spot radius $(2 \mathrm{~cm})$, pulse duration $(15 \mathrm{~ns})$, and repetition rate $(0.5 \mathrm{~Hz})$.

The laser is modeled as pulsed heat source and inserted in the heating equation as general inward heat

$$
\mathrm{Q}=\alpha * \operatorname{hf}(\mathrm{x}, \mathrm{y}, \mathrm{t}) * \mathrm{gf}(\mathrm{t})\left[\frac{\mathrm{W}}{\mathrm{m} 2}\right]
$$

Where $\alpha$ is the absorption coefficient,hf(x, $\mathrm{y}, \mathrm{t})$ is the Gaussian laser beam as in figure (1)

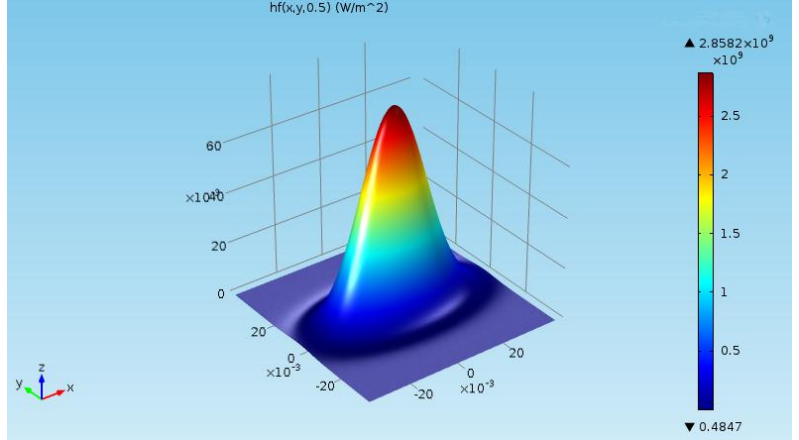

Figure 1. Laser beam used in the simulation.

gf(t) is the pulse function to represent the laser as pulsed train with pulse duration equals to $15 \mathrm{~ns}$ that represent the $\mathrm{ON}$ stage with the energy equals to $375 \mathrm{~mJ}$ per pulse ,and pulse separation is $2 \mathrm{~s}$ which is the OFF stage

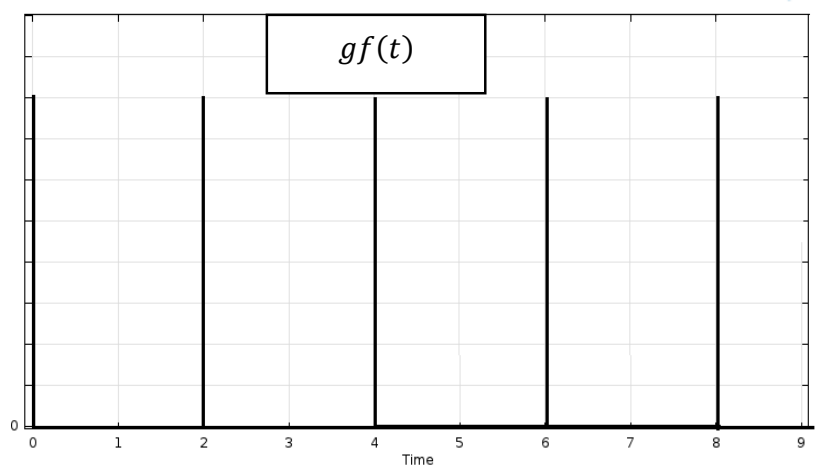

Figure 2.Pulsed function

The simulations were performed for different number of pulses and for all the nanocomposite samples, until the maximum temperature reaches the decomposition temperature for the specific nanocomposite.

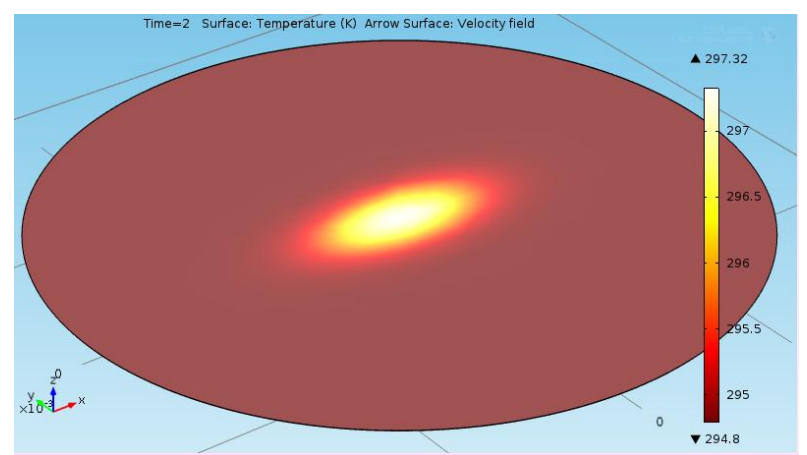

Figure 3. Temperature distribution within $2.5 \%$ sample after the first pulse.

Table (2) shows the simulation results. The maximum temperature after one pulse TMAX is found to increase as the nanocomposite doping is higher. As can be seen that after one pulse the maximum temperature increases from the initial temperature only $\left(1^{\circ} \mathrm{C}\right)$ for PVA, It is about $\left(30^{\circ} \mathrm{C}\right)$ for the $10 \%$ nanocomposite sample. 


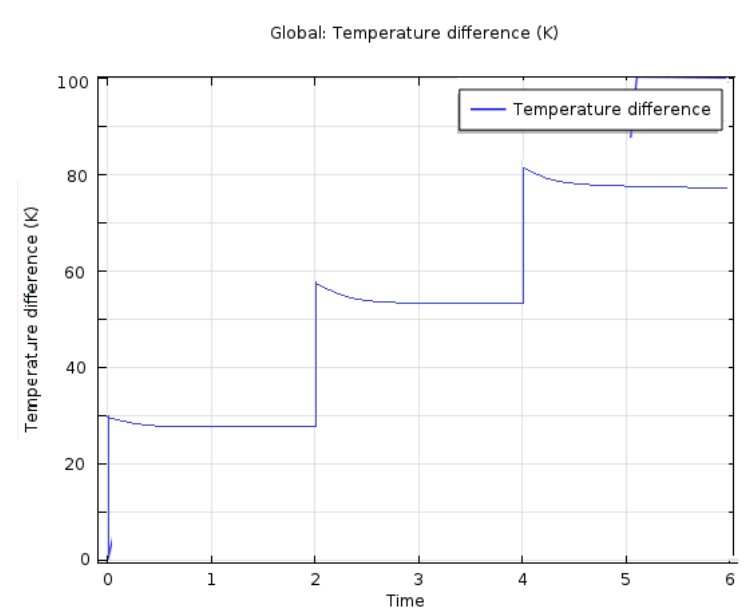

Figure 4. temperature change with time during simulation for sample $10 \%$.

This can be understood since the absorption coefficient increases by increasing $\mathrm{TiO}_{2}$ ratio. Heat diffusion in the thin film is faster for higher doped composites. It can be seen from the simulation that the PVA is hardly affected by the Nitrogen laser. Since the maximum temperature rose about $1^{\circ} \mathrm{C}$ and decreases before the next pulse .The laser gets more effective as the doping ration increases. And the decomposition temperature could be reached by lower fluencies as shown in table (2)

Table 2. Simulation values for maximum temperature after one pulse and the damage threshold

\begin{tabular}{|c|c|c|}
\hline $\begin{array}{c}\text { Sample } \mathbf{T i O}_{2} / \mathbf{P V A} \\
(\mathbf{w t} / \mathbf{w t} \%)\end{array}$ & $\begin{array}{c}\mathbf{T}_{\text {Max }} \\
{[\mathrm{C}]}\end{array}$ & $\begin{array}{c}\text { Damage threshold } \\
{[\mathrm{J}]}\end{array}$ \\
\hline 0 & 1 & 1.611 \\
\hline $1.5 \%$ & 5.5 & 0.836 \\
\hline $2.5 \%$ & 11 & 0.716 \\
\hline $5 \%$ & 13 & 0.328 \\
\hline $7.5 \%$ & 28 & 0.298 \\
\hline $10 \%$ & 30 & \\
\hline
\end{tabular}

\section{CONCLUSION}

Laser heat effect on TiO2 /PVA nanocomposie thin films were simulated using COMSOL 4.3. The nanoparticles increases laser absorption in the nanocomposite thin films, which causes lower damage threshold for the nanocomposites by increasing doping percentage.

\section{REFERENCES}

[1] Wehner M., Beckemper S., Jacobs P., Schillinger S., Schibur D., Gillner A. (2005) Processing of polycarbonate by high-repetition rate $\mathrm{ArF}$ excimer laser radiation, in Proceedings of the Third international WLT conference on Lasers in Manufacturing (LIM2005), Munich, Germany, 557- 561.

[2] Jassim, A. S., Dahham, N. A., \& Maric, M. Sh. (2010). Study of theoptical properties for $\mathrm{ZnS}$ thin film irradiated by Co2 laser. Ibn Al-Haitham Journal for Pure and Applied Science, 23(3), 58e67.

[3] Shan-Ting Hsu*, Huade Tan, Y. Lawrence Yao Polymer Degradation and Stability 97 (2012) 88e97

[4] Andrade, S. R., Jardini, A., Wolf Maciel, M. R., Maciel Filho, R., 2006, Numerical Simulation of Localized Cure of Thermosensitive Resin During Thermo Stereolithography Process (TSTL) J Appl Polym Sci 102, $2777-2783$

[5] Generating Micro- and Nanopatterns on Polymeric Materials Aranzazu del Campo, Eduard Arzt

[6] Frenk Kreith,The CRC handbook of thermal engineering, : CRC Press LLC, 2000

[7] Sajjan Kumar1, Rajpal Singh Bhoopal1, Pradeep Kumar Sharma1, Radhey Shyam Beniwal2, Ramvir Singh1* Open Journal of Composite Materials, 2011, 1, 10-18 